\title{
Helplessness-like escape deficits of NIH-HS rats predict passive behavior in the forced swimming test: Relevance for the concurrent validity of rat models of depression
}

\author{
Marta Palència ${ }^{1}$, Sira Díaz-Morán ${ }^{1}$, Carme Mont-Cardona ${ }^{1,2}$, Toni Cañete ${ }^{1}$, Gloria Blázquez ${ }^{1}$, \\ Esther Martínez-Membrives ${ }^{1}$, Regina López-Aumatell ${ }^{1,2}$, Adolf Tobeña ${ }^{1}$, Alberto Fernández-Teruel ${ }^{{ }^{*}}$ \\ ${ }^{1}$ Medical Psychology Unit, Department of Psychiatry \& Forensic Medicine, Institute of Neurosciences, School of Medicine, \\ Autonomous University of Barcelona, Barcelona, Spain \\ ${ }^{2}$ Welcome Trust Centre for Human Genetics, Oxford, UK \\ Email: ${ }^{*}$ albert.fernandez.teruel@uab.es
}

Received 25 January 2013; revised 27 February 2013; accepted 23 March 2013

Copyright (C) 2013 Marta Palència et al. This is an open access article distributed under the Creative Commons Attribution License, which permits unrestricted use, distribution, and reproduction in any medium, provided the original work is properly cited.

\begin{abstract}
The genetically heterogeneous NIH-HS rat stock has been characterized by its response to anxiety- and fear-inducing situations, thus leading to the conclusion that they are a rather anxious and passive coping type of rats. Taking advantage of these profiles, and knowing that they show very poor performance in the two-way active (shuttle box) escape/avoidance task, we have tested NIH-HS rats $(n=80)$ in the forced swimming test (FST) as well as we have studied escape response deficits (i.e. response failures) of the same animals in the two-way shuttle box task. They were also tested for anxiety in the elevated zero-maze. The goal of such a study was that of investigating whether there are associations or relationships among helplessness-like or passive coping responses between both models of depression, i.e. the FST and the helplessness-like escape deficits in the shuttle box task. The results for the first time show associations among responses from both depression models and that selecting rats for displaying extreme (active or passive) responses in one of the models predict in a coherent manner (according to the hypothesis) their behaviour in the other model. These findings are discussed in the context of the concurrent validity of both models of depression as well as concerning the possible relevance of NIH-HS rats as a tool for future studies on this field.
\end{abstract}

Keywords: Genetically Heterogeneous Rats; NIH-HS Stock; Forced Swimming Test; Helplessness; Passive Coping; Depression; Anxiety

"Corresponding author.

\section{INTRODUCTION}

The forced swimming test (FST), first introduced by Porsolt et al. [1], is a behavioral procedure used to reproduce in rodents passive coping responses to stress that may model certain aspects of human depression. This test has been widely used to evaluate the clinical efficacy of antidepressant treatments. Thus, antidepressant drugs with different pharmcodynamic properties (see [2]), as well as electroconvulsive shock, transcranial magnetic stimulation, and vagus nerve stimulation $[3,4]$ decrease the duration of immobility and increase active escapedirected behaviors (i.e. active swimming or struggling). The FST is also sensitive to a number of experimental models of predisposition to depression, including chronic mild stress and unpredictable vs. predictable acute stress $[5,6]$, and has been used as a marker of depressive-like behavior in selectively bred lines or strains of rodents [7-11].

The learned helplessness model of depression, first described by Overmier and Seligman [12], is based on the impairments of escape learning that follow exposure to inescapable (uncontrollable) electric shock. Such a cognitive impairment, jointly with several motivational/ emotional alterations (e.g. anhedonia), provides face validity to the model, while the syndrome reversibility by chronic antidepressant treatment lends predictive validity to it (for review see for instance [13]). While prior uncontrollable/unpredictable stressful (shock) experience is commonly used for induction of learned helplessness, some particular rodent strains/lines (or subpopulations within a given strain) provide models in which helplessness-like responses can be observed even without prior stress exposure, that is to say, animals selected according 
to a given behavioural criterion (related with emotionality/fearfulness; e.g. $[14,15]$ ), specific rat strains (e.g. the WKY rat strain; $[7,10,13,16])$ or selectively bred strains, i.e. psychogenetically or pharmacogenetically selected rodent strains (e.g. [9,11,17-21]), may provide "depresssion" models per se, without the need of using previous exposure to predisposing factors such as stressful experiences (see further in the "Discussion").

The "National Institutes of Health -N/NIH-Genetically Heterogeneous Rat Stock" (hereafter, NIH-HS rats) was developed by Hansen and Spuhler [22] with the aim of having a more naturalistic, genetically heterogeneous rat stock which could yield a broad-range distribution of responses to experimental conditions and could serve as a base population for selection studies. With this aim, the NIH-HS rat stock was formed through an eight-way cross among eight inbred rat strains (see "Methods" below; Hansen and Spuhler [22]). Recent genetic studies have demonstrated that the NIH-HS rat stock is a unique animal model for the simultaneous identification and fine mapping of QTLs (Quantitative Trait Loci) even to a gene resolution level (for reviews see [23,24]). From the phenotypic stand point, our behavioural and hormonal studies of the heterogeneous rat stock clearly indicate that the NIH-HS rat colony (established in our laboratory, at Autonomous University of Barcelona, in 2004) exhibits a behavioural "defensive" profile indicating that these animals are rather fearful and anxious, presenting a predominantly passive/reactive coping style as well as stressprone (i.e. enhanced) hormone response profile. Thus, the anxiety/fear and stress hormone response profiles of NIH-HS rats are much closer to the (high anxious, stress prone) passive coper RLA-I rats than to the (low anxious, stress resistant) proactive coper RHA-I rats [23,25-30].

Thus, taking advantage of the fact that we know the NIH-HS rats are, as a population, passive coping rats with very poor ability for the acquisition of the twoway - shuttle box-active escape/avoidance task (see [23, $25,27,28]$ ), we made the hypothesis that at least a subsample of the heterogeneous rat stock could display a kind of "spontaneous" (i.e. as we are not using any prior stress) helplessness in the shuttle box task, i.e. a relatively elevated number of escape failures (hereafter, response failures or "R failures"), and that such a "helpless" profile would show some associations with passive coping strategies in the forced swimming test (i.e. relatively high levels of immobility and/or low levels of struggling -escape-directed- behaviour).

It is important to notice here that no previous work has addressed the issue of whether helplessness-like responses (i.e. response failures) in the shuttle box escape task and passive/depressive-like behaviour in the FST (i.e. high levels of immobility and/or low levels of struggling) are related or associated to each other in hetero- geneous (outbred, unselected) rats, an issue that is important for the concurrent validity of both procedures as models of depressive-like symptoms.

\section{METHODS}

\subsection{Animals}

Subjects were 80 male NIH-HS rats, coming from 40 different litters and being 3 months old at the beginning of the experiment. They were housed in pairs in macrolon cages $(50 \mathrm{~cm} \times 25 \mathrm{~cm} \times 14 \mathrm{~cm})$, maintained with food and tap water available ad libitum, under conditions of controlled temperature $\left(22^{\circ} \mathrm{C} \pm 2^{\circ} \mathrm{C} ; 50 \%-70 \%\right.$ humidity) and a 12-h light/12-h dark cycle (lights on at 08:00 h).

\subsection{Procedure and Apparatus}

Experiments were performed during the light cycle, between 09:00 and 19:00 h., and in accordance with the Spanish legislation on "Protection of Animals Used for Experimental and Other Scientific Purposes" and the European Communities Council Directive (86/609/EEC) on this subject. The experimental protocol was approved by the Autonomous University of Barcelona Ethics committee. Three behavioral tests were administered (in order: FST, elevated zero-maze and two-way escape/ avoidance-shuttle box-task), with 1 week elapsing between each two consecutive tests. The sequence and the characteristics of the tests were as follows:

\subsubsection{Forced Swimming Test (FST)}

The procedure used was very similar to that described by Porsolt et al. [1] and modified by Detke et al. [31] (see also [32]). Swim sessions were conducted by plunging the rats in individual vertical plastic cylinders $(60 \mathrm{~cm}$ tall X $19 \mathrm{~cm}$ diameter), containing $40 \mathrm{~cm}$ of water at $24^{\circ} \mathrm{C}$ $26^{\circ} \mathrm{C}$. The experimental procedure consisted of two sessions: an initial 15-min "pretest" followed $24 \mathrm{~h}$ later by a 5 -min test. Following swim sessions, rats were removed from the cylinders, gently dried with paper towels and returned to their home cages. Water was changed for each rat. The apparatus was situated in a black-painted testing room dimly illuminated with white fluorescent light $(36 \mathrm{~W})$ situated in the ceiling ( 2.5 height), and the behavior was videotaped and measured outside the testing room. Variables recorded during two sessions, were: 1) Immobility: rat was making only those movements necessary to keep its head above water; 2) Struggling: rat was making active swimming motions, thus displaying vigorous (escape-directed) activity with its four legs and keeping a vertical position [31].

\subsubsection{Elevated Zero-Maze (ZM)}

The maze, similar to that described by Shepherd et al. 
[33], comprised an annular platform (105 $\mathrm{cm}$ diameter; $10 \mathrm{~cm}$ width) made of black plywood and elevated to 65 $\mathrm{cm}$ above the ground level. It had two open sections (quadrants) and two enclosed ones (with walls $40 \mathrm{~cm}$ height). The subject was placed in an enclosed section facing the wall. The apparatus was situated in a black testing room, dimly illuminated with red fluorescent light, and the behavior was videotaped and measured outside the testing room. Time spent in the open sections (Time), number of entries in the open sections (Entries), number of stretched attend postures (SAP) were measured for 5 minutes (for details of the validity of the test see references in [26-29,33].

\subsubsection{Two-Way Active, Shuttle Box Escape/Avoidance Task (SH)}

The experiment was carried out with 2 identical shuttle boxes (Letica, Panlab, Barcelona, Spain), each placed within independent, sound-attenuating boxes constructed of plywood. A dim and diffuse illumination was provided by a fluorescent bulb placed behind the opaque wall of the shuttle boxes. The experimental room was kept dark. The shuttle boxes consisted of two equally sized compartments $(25 \mathrm{~cm} \times 25 \mathrm{~cm} \times 28 \mathrm{~cm})$, connected by an opening $(8 \mathrm{~cm} \times 10 \mathrm{~cm})$. A $2400-\mathrm{Hz}, 63-\mathrm{dB}$ tone plus a light (from a small, 7-W lamp) functioned as the CS (conditioned stimulus). The US (unconditioned stimulus), which commenced at the end of the CS, was a scrambled electric shock of $0.7 \mathrm{~mA}$ delivered through the grid floor. Once the rats were placed into the shuttle box, a 4-min familiarization period elapsed before training commenced. Each training trial consisted of a 10 -s CS, followed by a 20 -s US. The CS or US was terminated when the animal crossed to the other compartment, with crossing during the CS being considered as an avoidance response and during the US as an escape response. Once a crossing had been made or the shock (US) discontinued, a 60-s inter-trial interval (ITI) was presented during which crossings (ITC) were also scored. Training consisted of a single 50-trial session.

The variables recorded were 1) "context-conditioned freezing", i.e. the time spent freezing (Freezing) during the first five inter-trial intervals of the training session (when no rat had made any avoidance response); 2) the number of escape response failures during training (" $R$ failures", i.e. the rat does not cross to the opposite compartment neither during CS nor US presentation; this is the first "helplessness"-like variable); 3) the average response latency for the first ten trials ("10Latency", because this is the phase of training where most " $R$ failures" are present, about $90 \%$ of them; this is the second "helplessness"-like variable); and 4) the number of avoidances (Avoidances) during the whole 50-trial training session. Context-conditioned freezing, was measured by two trained observers (between-observer reliability, $\mathrm{r}>$ 0.95 ) as the time a rat spent completely motionless except for breathing movements (see details and references on the validity of this task in $[26-30,34])$.

\subsection{Statistical Analysis}

A correlation matrix and obliquely-rotated (oblimin direct) factor analysis were performed to study the associations among the different and most relevant dependent variables (10 variables) of the three behavioral tests (these 10 representative variables were selected according to - and to be consistent with - the same criteria we have used in previous studies; see [26-30]). Finally, we constituted extreme subgroups of the NIH-HS rats by selecting animals with values $\pm 1 \mathrm{SD}$ for (see Tables 1 and 4): 1) "Immobility5" and "Struggling5" combined (thus an extreme "Passive coping" subgroup-i.e. low "Struggling5" and high "Immobility5", $\mathrm{n}=8$-and an extreme "Active coping" subgroup-i.e. high "Struggling5" and low "Immobility5", $\mathrm{n}=13$-were constituted); 2) extreme scores in "R failures" (i.e. response failures), thus forming a "No R failures" $(\mathrm{n}=30)$ sub-

Table 1. Descriptive statistics of the most relevant behavioral variables from the elevated zero-maze test, the forced swimming test and the shuttle box training session.

\begin{tabular}{ccc}
\hline Forced swimming test & Mean \pm SEM & SD \\
\hline Immobility15' & $637.8 \pm 25.5$ & 180.3 \\
Struggling15' & $44.7 \pm 4.1$ & 28.9 \\
Immobility5' & $189.0 \pm 8.0$ & 69.6 \\
Struggling5' & $33.4 \pm 3.4$ & 29.7
\end{tabular}

Elevated zero maze test

$\begin{array}{ccc}\text { Entries } & 4.7 \pm 0.4 & 3.5 \\ \text { SAP } & 9.5 \pm 0.9 & 7.5\end{array}$

Shuttle box training session

$\begin{array}{ccc}\text { Freezing (s) } & 212.3 \pm 4.4 & 40.2 \\ \text { Avoidances (\#) } & 5.1 \pm 0.9 & 8.4 \\ \text { R failures (\#) } & 3.3 \pm 0.7 & 6.6 \\ \text { 10Latency (s) } & 13.9 \pm 0.4 & 3.7\end{array}$

Mean \pm SEM (and SD -standard deviations-) are shown. "Immobility15", and "Struggling 15"': measures (s) from the first 15-min swimming session. "Immobility5" and "Struggling5": measures (s) from the second 5-min swimming session. "Entries" (n): number of entries in the open sections in the Elevated zero-maze; "SAP": number of stretched-attend postures were measured for 5 minutes in the Elevated zero maze; "Freezing": total time of context-conditioned freezing (s) during five minutes (i.e. the first 5 intertrial intervals in the shuttle box training session). "Avoidances": total number of avoidances in the 50-trial shuttle box session (n); "R failures": total number of escape/avoidance response failures (i.e. no compartment changes when the CS or US were present) during the shuttle box training session; "10Latency": the average response latency for the first ten trials (i.e. when most "R failures" occur) in the shuttle box training session; $n=80$. 
group and a "High R failures" (n=10) subgroup; and 3) extreme scores in "10Latency" (the average response latency for the first 10 trials of shuttle box escape training), thus forming a "Short 10Latency" ( $\mathrm{n}=15)$ subgroup and a "Long 10Latency" $(n=14)$ subgroup (see Table 1 for descriptive statistics - mean $\pm 1 \mathrm{SD}$ - of the whole sample, and Table 4 for descriptions and comparisons between those extreme subgroups).

Student's t-tests for independent samples were used to analyze the differences between the values of each pair of extreme subgroups.

\section{RESULTS}

Table 1 shows the descriptive statistics of the whole NIH-HS sample for variables from the ZM, FST and the shuttle box training session.

Concerning the main hypothesis of the present study, the correlation matrix (Table 2) mainly shows: 1) significantly moderate to high correlations among FST measures $(r=0.68$ between Struggling 15' and Struggling5'; $r$ $=0.43$ between Immobility $15^{\prime}$ and Immobility $5^{\prime}$, and negative correlation- $r=-0.56$ - between Struggling5' and Immobility5'); 2) a low but significant negative correlation between Struggling5' and "10Latency" ( $\mathrm{r}=$ -0.25 ; and, 3 ) as expected, there are positive correlations among shuttle box variables (e.g. $r=0.31$, between Freezing and "R failures", and $r=0.64$ between "10Latency" and "R failures") (see Table 2).

Obliquely-rotated factor analysis (Direct oblimin), to make more conceptual sense to those correlational patterns, was then applied to the 10 target variables (Table 3). A four-factor solution was obtained in which the first factor was dominated by FST variables, the second factor was especially represented by "Immobility" variables, the third is essentially a ZM factor and the fourth is exclusively a shuttle box task factor (see Table 3(a)). This first test-related 4-factor structure was then reduced to a twofactor solution after applying the Catell's Scree test (Table 3(b); see the criteria for this test in $[25,26]$ ) according to the eigenvalues of the first two factors. This solution (Direct Oblimin) showed two independent factors which explained $42.5 \%$ of the variance (correlation between factors $=0.078$; Table 3(b)). Factor 1, tentatively named "Coping style", grouped FST variables ("Struggling5"' and "Struggling15"', loading 0.74 and 0.85 respectively, and "Immobility15", loading -0.66) in association with the two helplessness-like measures from the shuttle box escape task ("10Latency" and "R failures", loadings of -0.29 to -0.38 , respectively) and also with low loadings of ZM measures (SAP and "Entries", loading 0.31 and 0.26 respectively). Factor 2 mainly represented conditioned conflict (thus, temptatively named "Conflict solving"; [26,27]), as indicated by the loadings of shuttle box task variables (loadings of $-0.70,-0.63$, -0.44 for "R failures", "10Latency" and "Freezing", and 0.62 for "Avoidances") (Table 3(b)).

Table 4(a) shows that selection for displaying extreme (combined) "Immobility5"" and "Struggling5"” scores, thus obtaining a "Passive coping" subgroup and an "Active coping" subgroup, leads to differences in helplessness-related responses, as the "Passive coping" group shows higher number of "R failures" $(\mathrm{t}(19)=2.1, \mathrm{p}<$ $0.05)$ and longer "10Latency" $(\mathrm{t}(19)=3.1, \mathrm{p}<0.01)$ than the "Active coping" subgroup (Table 4(a)). Most outstandingly, when selecting subgroups of rats with relatively high helplessness-like behaviour (i.e. "High $\mathrm{R}$

Table 2. Correlation matrix among the main variables from the elevated zero-maze test, the forced swimming test and the shuttle box training session.

\begin{tabular}{|c|c|c|c|c|c|c|c|c|c|c|}
\hline & Immobility $15^{\prime}$ & Struggling $15^{\prime}$ & Immobility5' & Struggling5' & Entries & SAP & Freezing & Avoidances & $\mathrm{R}$ failures & 10Latency \\
\hline Immobility $15^{\prime}$ & 1 & & & & & & & & & \\
\hline Struggling $15^{\prime}$ & -0.15 & 1 & & & & & & & & \\
\hline Immobility5' & $0.43^{* *}$ & -0.18 & 1 & & & & & & & \\
\hline Struggling5' & -0.11 & $0.68^{* *}$ & $-0.56^{* *}$ & 1 & & & & & & \\
\hline Entries & 0.01 & -0.02 & -0.19 & 0.10 & 1 & & & & & \\
\hline SAP & 0.15 & -0.02 & -0.19 & 0.20 & $0.37^{* *}$ & 1 & & & & \\
\hline Freezing & -0.13 & -0.06 & -0.04 & -0.16 & -0.02 & 0.03 & 1 & & & \\
\hline Avoidances & 0.23 & -0.02 & 0.03 & -0.06 & 0.04 & $0.31^{* *}$ & -0.23 & 1 & & \\
\hline $\mathrm{R}$ failures & -0.18 & -0.18 & -0.04 & -0.19 & -0.08 & -0.03 & $0.31^{* *}$ & -0.19 & 1 & \\
\hline 10Latency & -0.12 & -0.17 & 0.16 & $-0.25^{*}$ & $-0.51^{* *}$ & -0.10 & 0.19 & -0.19 & $0.64^{* *}$ & 1 \\
\hline
\end{tabular}

${ }^{*} \mathrm{p} \leq 0.05$ Pearson's correlation coefficient. ${ }^{* *} \mathrm{p} \leq 0.01$ Pearson's correlation coefficient. ${ }^{* * *} \mathrm{p} \leq 0.001$ Pearson's correlation coefficient; $\mathrm{n}=80$. See Table 1 for details of the variables. 
Table 3. Factor analyses of the most relevant behavioral variables (five-and two-factor solutions). (a) First obliquely-rotated factor analysis: four-fold solution; (b) Second obliquely-rotated factor analysis: two-fold solution.

(a)

\begin{tabular}{|c|c|c|c|c|}
\hline & Factor 1 & Factor 2 & Factor 3 & Factor 4 \\
\hline \multicolumn{5}{|c|}{ Elevated zero-maze } \\
\hline Entries (\#) & - & - & 0.74 & - \\
\hline $\operatorname{SAP}(\#)$ & - & 0.51 & 0.70 & - \\
\hline \multicolumn{5}{|c|}{ Forced swimming test } \\
\hline Immobility $15^{\prime}$ & - & 0.78 & - & - \\
\hline Struggling15' & 0.86 & - & - & - \\
\hline Immobility5' & -0.53 & 0.46 & -0.53 & - \\
\hline Struggling5' & 0.93 & - & - & - \\
\hline \multicolumn{5}{|c|}{ Two-way shuttle box avoidance session } \\
\hline Freezing (s) & - & -0.31 & 0.37 & 0.41 \\
\hline Avoidances (\#) & - & 0.70 & - & -0.26 \\
\hline R failures (\#) & - & - & - & 0.87 \\
\hline 10Latency (s) & - & - & - & 0.85 \\
\hline Eigenvalues & 2.2 & 2.05 & 1.49 & 1.03 \\
\hline Explained variance: 6 & & & & \\
\hline
\end{tabular}

(b)

Factor 1 "Coping style"

Factor 2 "Conflict solving"

Elevated zero-maze

Entries (\#)

0.26

SAP (\#)

0.31

0.32

Forced swimming test

Immobility $15^{\prime}$

0.6

Struggling $15^{\prime}$

0.74

Immobility5'

$-0.66$

0.33

Struggling $5^{\prime}$

0.85

Two-way shuttle box avoidance session

Freezing (s)

$\begin{array}{ll}- & -0.44\end{array}$

Avoidances (\#)

$$
-
$$

$\mathrm{R}$ failures (\#)

$-0.29$

$-0.70$

10Latency (s)

$-0.38$

$-0.63$

Explained variance: $42.5 \%$

Correlation between factor $=0.078$

Only loadings with absolute values $\geq 0.25$ are shown. (a) Oblique five-factor solution (direct oblimin) with 10 selected variables (factors with eigenvalues greater than 1); (b) Two-factor solution and correlation between factors, showing that both factors are orthogonal (independent); $\mathrm{n}=80$. See Table 1 for details of the variables. 
Table 4. Comparisons between subgroups of N/Nih-HS rats selected according to their extreme (high vs. low) scores in relevant variables from the forced swimming test or from the shuttle box training session. (a) Subgroups with extreme values in "Struggling5"” \& "Immobility5"; (b) Subgroups extreme in "R failures"; (c) Subgroups extreme in "10Latency".

(a)

\begin{tabular}{|c|c|c|c|}
\hline & "Passive coping" $(\mathrm{n}=8)$ & “Active coping” (n = 13) & Student's " $t$ " \\
\hline ELEVATED ZERO-MAZE: Entries & $4.6 \pm 0.9$ & $5.1 \pm 1.3$ & 0.3 \\
\hline SAP & $7.6 \pm 0.7$ & $12.8 \pm 5.0$ & 0.9 \\
\hline FORCED SWIMMING: Immobility15' & $837.0 \pm 20.0$ & $546.4 \pm 51.0$ & $3.7^{* *}$ \\
\hline Struggling15' & $29.5 \pm 0.5$ & $66.5 \pm 4.9$ & $4.2^{* * *}$ \\
\hline Immobility5' & $291.3 \pm 4.5$ & $97.2 \pm 9.7$ & $13.9^{* * *}$ \\
\hline Struggling5' & $2.3 \pm 0.9$ & $78.5 \pm 8.0$ & $9.0^{* * *}$ \\
\hline SHUTTLE BOX: Avoidances (\#) & $0.7 \pm 0.3$ & $1.9 \pm 1.7$ & 0.5 \\
\hline $\mathrm{R}$ failures (\#) & $4.0 \pm 1.6$ & $1.1 \pm 0.4$ & $2.1^{*}$ \\
\hline Freezing (s) & $221.9 \pm 8.8$ & $208.6 \pm 13.2$ & 0.8 \\
\hline 10Latency (s) & $17.3 \pm 1.7$ & $12.3 \pm 0.7$ & $3.1^{* *}$ \\
\hline
\end{tabular}

(b)

\begin{tabular}{cccc}
\hline & "No R failures" $(\mathrm{n}=30)$ & "High R failures" $(\mathrm{n}=10)$ & Student's "t" \\
\hline ELEVATED ZERO-MAZE: Entries & $5.1 \pm 0.6$ & $4.0 \pm 0.9$ & 0.8 \\
SAP & $9.5 \pm 1.1$ & $12.8 \pm 5.0$ & 0.6 \\
FORCED SWIMMING: Immobility15, & $664.7 .0 \pm 35.1$ & $546.7 \pm 161.2$ & 1.0 \\
Struggling15, & $44.8 \pm 4.3$ & $16.3 \pm 5.3$ & $2.2^{*}$ \\
Immobility5, & $189.4 \pm 10.8$ & $199.0 \pm 26.1$ & 0.4 \\
Struggling5, & $32.1 \pm 4.1$ & $15.4 \pm 3.9$ & $1.9+$ \\
SHUTTLE BOX: Avoidances (\#) & $7.9 \pm 1.9$ & $2.8 \pm 1.5$ & 1.5 \\
R failures (\#) & $0 \pm 0.0$ & $19 \pm 3.4$ & $14.1^{* * *}$ \\
Freezing (s) & $202.9 \pm 6.4$ & $241.0 \pm 7.6$ & $21.1 \pm 1.3$ \\
10Latency (s) & $14.1 \pm 1.6$ & $2.5^{*}$ \\
\hline
\end{tabular}

(c)

\begin{tabular}{|c|c|c|c|}
\hline & "Short 10Latency" $(\mathrm{n}=15)$ & "Long 10 Latency" $(\mathrm{n}=14)$ & Student's " $\mathrm{t}$ " \\
\hline ELEVATED ZERO-MAZE: Entries & $4.3 \pm 0.9$ & $3.9 \pm 0.5$ & 0.4 \\
\hline SAP & $8.4 \pm 0.7$ & $8.0 \pm 2.4$ & 0.4 \\
\hline FORCED SWIMMING: Immobility15' & $624.3 \pm 62.3$ & $535.55 \pm 33.1$ & 0.8 \\
\hline Struggling $15^{\prime}$ & $47.5 \pm 6.9$ & $22.9 \pm 7.9$ & $2.2^{*}$ \\
\hline Immobility5, & $187.7 \pm 18.9$ & $204.9 \pm 19.9$ & 0.6 \\
\hline Struggling5 & $45.1 \pm 9.4$ & $16.4 \pm 4.4$ & $2.8^{* *}$ \\
\hline SHUTTLE BOX: Avoidances (\#) & $7.1 \pm 2.6$ & $1.9 \pm 0.9$ & 1.4 \\
\hline $\mathrm{R}$ failures (\#) & $0.6 \pm 0.4$ & $12.6 \pm 2.8$ & $4.3^{* * *}$ \\
\hline Freezing (s) & $200 \pm 10.1$ & $226.1 \pm 9.9$ & 1.8 \\
\hline 10Latency (s) & $10.8 \pm 0.1$ & $21.7 \pm 0.7$ & $16.7^{* * *}$ \\
\hline
\end{tabular}

(a) Values (mean \pm SEM) of NIH-HS subgroups selected for their extreme ( \pm 1 SD; see Table 1) scores in "Struggling5" + Immobility5". Thus an extreme "Passive coping" subgroup (i.e. low "Struggling5" and high "Immobility5", $\mathrm{n}=8$ ) and an extreme "Active coping" subgroup (i.e. high "Struggling5" and low "Immobility5", $\mathrm{n}=13$ ) were constituted; (b) Values (mean $\pm \mathrm{SEM}$ ) of NIH-HS subgroups selected for their extreme ( \pm 1 SD; see Table 1) scores in "R failures" (i.e. response failures), thus forming a "No R failures" $(\mathrm{n}=30)$ subgroup and a "High R failures" $(\mathrm{n}=10)$ subgroup; (c) Values (mean \pm SEM) of NIH-HS subgroups selected for their extreme ( $\pm 1 \mathrm{SD}$; see Table 1) scores in "10Latency" (the average response latency for the first 10 trials of shuttle box training), thus forming a "Short 10Latency" $(\mathrm{n}=15)$ subgroup and a "Long 10Latency" $(\mathrm{n}=14)$ subgroup. $+\mathrm{p}<0.05$ one-tailed (under the hypothesis that lower levels of "Struggling5" were expected in the forced swimming test in rats showing the relatively highest levels of response failures-i.e. "High R failures"- $)$. ${ }^{*} \mathrm{p}<0.05$, ${ }^{* *} \mathrm{p}<0.01,{ }^{* *} \mathrm{p}<0.001$ (two-tailed). All comparisons made with Student's t-test for independent samples. See variable symbols in Table 1. 
failures", "Long 10Latency"; Tables 4(b) and (c), respectively), these also show significantly lower levels of "Struggling5"" and "Struggling15" than the corresponding "No R Failures" and "Short 10Latency" subgroups (see Student's t-test comparisons in Tables 4(b) and (c)).

\section{DISCUSSION}

The present study shows, for the first time, the relationship/associations between a passive coping style in the forced swimming test (FST; an inescapable stress situation and an animal model of depressive symptoms) and the helplessness-like behavioural profile in the twoway-shuttle box- escape/avoidance task, as indicated by "R failures" and "10Latency" (two variables which indicate escape deficits). Response failures in this task, either under "fixed ratio 1" - as in the present study_or "fixed ratio 2 " reinforcement programs, have been traditionally considered as an index of learned helplessness and, therefore, a behavioural phenotype with some validity for modelling some human depressive symptoms (e.g. [13]). In our study, "R failures" and "10Latency" (response latency during the first 10 escape/avoidance trials, where most $-90 \%$ - "R failures" occur) are associated with struggling and immobility responses in the FST in the expected direction as indicated by the following evidence: 1) the higher the immobility and the lower the struggling levels, the higher the number of response failures and the longer "10Latency" values, as indicated by the structure of the first factor in the factor analysis (see the two-fold solution in Table 3(b)); 2) the subgroup of rats selected for their extremely "passive" coping style (i.e. high "Immobility5"' and low "Struggling5"' levels; Table 4(a)) in the FST display more "R failures" and longer "10Latency" values than the subgroup of rats selected for their "active coping" style (i.e. low "Immobility5" and high "Struggling5"" levels) in the FST (see Table 4(a)); 3) likewise, the subgroup of NIH-HS rats selected for showing "High R failures" (Table 4(b)) or "Long 10Latency" (Table 4(c)) in the shuttle-box escape/avoidance task (let us say, the "helpless" rat subgroup) show a predominantly passive coping style, and display lower levels of "Struggling5"' and "Struggling15"' responses than the "No R failures" or "Short 10Latency" subgroups (see Tables 4(b) and (c), respectively).

It is outstanding that none of the three criteria used for generating the extreme "helpless", i.e. active vs passive coping, subgroups (represented in Tables 4(a)-(c)), led to significant differences in typical anxiety variables from the elevated zero-maze test, such as SAP and "Entries in open sections" ([26-29]; see Tables 4(a)-(c)). Moreover, it is important to notice that all the above-mentioned differences between the selected (extreme) subgroups appear in absence of apparent gross motor differences be- tween them, as indirectly indicated by the number of "Entries" in the elevated zero-maze (see Tables 4(a)-(c)) or by the number of "Intertrial crossings" during the shuttle box session (i.e. crossings performed during the 50 intertrial intervals - i.e. no CS nor US present-), which were $16.2 \pm 2.1$ and $23.5 \pm 4.5$ (mean \pm SEM; not significant difference) for the "passive coping" and "active coping" subgroups, respectively (corresponding to Table 4(a) subgroups).

In studies of learned helplessness, prior inescapable stress is commonly used to induce subsequent helpless behavior that is measured-among others - in the twoway shuttle box escape/avoidance task (e.g. [12,14,15]; for a review see [13]). In some cases, however, rats can be prone to experience helplessness-like symptoms (or to display passive coping strategies when facing stressful situations) as a product of selective breeding or some types of selection according to a behavioural criterion (e.g. $[11,14,15,25,32])$. This is the case of the Roman Low-Avoidance rats (RLA rats; e.g. [32]) and the Flinders Sensitive Line (e.g. [9]), to mention just two examples, which have been proposed as putative valid models of depression per se (as well as models of predisposition to stress-induced depression/helplessness) because they show passive coping responses under stress/conflict situations, helplessness-like responses in the two-way escape/avoidance task (even without any prior stress) and in the forced swimming test and relatively high stressinduced HPA-axis responses (in the case of RLA rats; e.g. [9,18,20,25,32]). Moreover, antidepressants are effective in reducing depressive symptoms in both the RLA and FSL rat lines/strains, while being devoid of effects on their RHA and FRL counterparts [9,32]. A case similar to the RLA line/strain appears to be that of NIH-HS rats, as this heterogeneous rat stock shows predominantly passive (i.e. reactive) coping responses when facing a variety of fear- or anxiety-inducing situations (e.g. conditioned conflict; [25-29]), elevated endocrine responses to stress and predominantly passive behaviour in both sessions of the forced swimming test (e.g. [23,25,30]). Actually, in most of these behavioural and endocrine responses, including their extremely poor ability to acquire/perform the two-way shuttle box escape/avoidance task, NIH-HS rats closely resemble RLA rats (e.g. the number of "R failures" and "avoidances" made by NIHHS rats in a two-way shuttle box escape/avoidance session are very similar to the usual scores of RLA rats; e.g. see $[23,25,27,28])$.

In connection with the previous arguments, it is worth to point out that one of the eight founder strains of the NIH-HS rat stock is the WKY (Wistar-Kyoto) rat strain. In this sense, it is interesting that WKY rats have become one of the most accepted models for depression research (e.g. see $[7,10,16,35-38])$, thus showing a predominantly 
passive coping profile in the forced swimming test, in the hole board, in the open-field test and in the acquisition of two-way escape/avoidance in the shuttle box, as well as relatively high stress-induced corticosterone and ACTH levels [35,37-40]. Our studies suggest therefore that NIHHS rats have retained some of the most relevant phenotypic characteristics of the WKY rat strain.

To sum up, the present is to our knowledge the first study providing evidence that there is some relationship between behaviour in the FST and in the two-way shuttle box escape task, i.e. a relationship/association between passive vs. active behaviour in the FST and "escape deficits/helplessness-like responses" in the two-way escape/ avoidance task, thus providing further support to the (concurrent) validity of these models of depressive symptoms.

Thus, the NIH-HS rat stock can be proposed as a model of depressive-like symptoms per se, which presents some face validity and concurrent validity especially because, other than the evidence that these rats are passive coping and stress-prone animals [23,25], there is an important subpopulation of them that spontaneously (i.e. without any prior stress induction) develop helplessness-like symptoms such as high levels of "R failures" (see Tables 4(b) and (c)) in the two-way escape/ avoidance-shuttle box - task, which are paralleled by (associated to) low levels of struggling and high levels of immobility in the forced swimming test (see Table 4(a)).

Further studies will be needed to determine whether it has predictive validity. In this regard, it would be interesting to carry out studies to evaluate the (hypothetically high) sensitivity of NIH-HS rats to develop stress-(uncontrollable shock)-induced "depression" and whether it is reversible by antidepressant drug treatment, provided that the reported increased hormonal (HPA) responses to acute stress [25] and the markedly passive coping style (under aversive/conflicting situations) of NIH-HS rats clearly support the hypothesis that they should show elevated sensitivity to various stress-induced deficits and to develop (enhanced) learned helplessness as a consequence of stressful experiences.

If studies devoted to test other aspects of (predictive, construct) validity of this "helplessness"-like subpopulation (as a model of depression) were successful, then studying predisposition to depression with the NIH-HS rat stock would have potential advantages, provided the genetic heterogeneity of the stock and the large number of genetic recombinants accumulated along many outbreeding generations (e.g. $[23,24])$.

\section{ACKNOWLEDGEMENTS}

Supported by grants for the MICINN (SAF2009-10532), "Fundació La Maratò TV3" (ref. 092630/31), 2009SGR-0051, EURATRANS consor- tium (grant agreement HEALTH-F4-2010-241504) and the Welcome Trust (UK). C.M-C is recipient of a FPI (2010; MICINN) PhD fellowship.

\section{REFERENCES}

[1] Porsolt, R.D., Le Pichon, M. and Jalfre, M. (1977) Depression: A new animal model to antidepressant treatments. Nature, 266, 730-732. doi: $10.1038 / 266730 \mathrm{a} 0$

[2] Cryan, J.F., Valentino, R.J. and Lucki, I. (2005) Assessing substrates underlying the behavioral effects of antidepressants using the modified rat forced swimming test. Neuroscience \& Biobehavioral Reviews, 29, 547-569. doi:10.1016/j.neubiorev.2005.03.008

[3] Fleischmann, A., Prolov, K., Abarbanel, J. and Belmakerm, R.H. (1995) The effect of transcranial magnetic stimulation of rat brain on behavioral models of depression. Brain Research, 699, 130-132. doi:10.1016/0006-8993(95)01018-Q

[4] Krahl, S.E., Senanayake, S.S., Pekary, A.E. and Sattin, A. (2004) Vagus nerve stimulation (VNS) is effective in a rat model of antidepressant action. Journal of Psychiatric Research, 38, 237-240. doi:10.1016/j.jpsychires.2003.11.005

[5] Willner, P. (2005) Chronic mild stress (CMS) revisited: Consistency and behavioural-neurobiological concordance in the effects of CMS. Neuropsychobiology, 52, 90-110. doi:10.1159/000087097

[6] Fernández-Teruel, A. (2008) Farmacología de la conducta: De los psicofármacos a las terapias psicológicas (Behavioral Pharmacology: From drug treatment to psychological therapies). Servei de Publicacions de la Universitat Autònoma de Barcelona, Barcelona.

[7] Armario, A., Gavaldà, A. and Martí, J. (1995) Comparison of the behavioural and endocrine response to forced swimming stress in five inbred strains of rats. Psychoneuroendocrinology, 20, 879-890. doi:10.1016/0306-4530(95)00018-6

[8] López-Rubalcava, C. and Lucki, I. (2000) Strain differences in the behavioral effects of antidepressant drugs in the rat forced swimming test. Neuropsychopharmacology, 22, 191-199. doi:10.1016/S0893-133X(99)00100-1

[9] Overstreet, D.H., Friedmanb, E., Mathé, A.A. and Yadidd, G. (2005) The Flinders Sensitive Line rat: A selectively bred putative animal model of depression. Neuroscience \& Biobehavioral Reviews, 29, 739-759. doi:10.1016/j.neubiorev.2005.03.015

[10] Paré, W.P. (1989) Behavioral despair test predicts stress ulcer in WKY rats. Physiology \& Behavior, 46, 483-487. doi:10.1016/0031-9384(89)90025-5

[11] Weiss, J.M., Cierpial, M.A. and West, C.H. (1999) Selective breeding of rats for high and low motor activity in a swim test: Toward a new animal model of depression. Pharmacology Biochemistry and Behavior, 61, 49-66. doi:10.1016/S0091-3057(98)00075-6

[12] Overmier, J.B. and Seligman, M.E. (1967) Effects of 
inescapable shock upon subsequent escape and avoidance responding. Journal of Comparative \& Physiological Psychology, 63, 28-33. doi:10.1037/h0024166

[13] Willner, P. and Mitchell, J. (2002) The validity of animal models of predisposition to depression. Behavioural Pharmacology, 13, 169-188.

doi:10.1097/00008877-200205000-00001

[14] del Real, P.T., Gibert-Rahola, I., Leonsegui, J.A. and Mico, J.A. (1991) Relationship between emotivity and susceptibility to the learned helplessnsess model of depression in the rat. In: Olivier, B., Mos, J. and Slangen, J.L., Eds., Animals Models in Psychopharmacology, Birkhauser Verlag, Basel, 217-224.

[15] del Real, P.T., Costela, C. and Gibert-Rahola, J. (1998) Neonatal handling reduces emotional reactivity and susceptibility to Learned Helplessness. Involvement of catecholaminergic systems. Life Sciences, 62, 37-50. doi:10.1016/S0024-3205(97)01036-9

[16] Paré, W.P. (1989) Stress ulcer susceptibility and depression in wistar Kyoto (WKY) rats. Physiology \& Behavior, 46, 993-998. doi:10.1016/0031-9384(89)90203-5

[17] Bougarel, L., Guitton, J., Zimmer, L., Vaugeois, J.M. and El Yacoubi M. (2001) Behaviour of a genetic mouse model of depression in the learned helplessness paradigm. Psychopharmacology, 215, 595-605. doi:10.1007/s00213-011-2218-3

[18] Carrasco, J., Márquez, C., Nadal, R., Tobeña, A., FernándezTeruel, A. and Armario, A. (2008) Characterization of central and peripheral components of the hypothalamuspituitary-adrenal axis in the inbred Roman rat strains. Psychoneuroendocrinology, 33, 437-445. doi:10.1016/j.psyneuen.2008.01.001

[19] Escorihuela, R.M., Fernández-Teruel, A., Gil, L., Aguilar, R., Tobeña, A. and Driscoll, P. (1999) Inbred Roman high- and low-avoidance rats: Differences in anxiety, novelty-seeking, and shuttlebox behaviors. Physiology \& Behavior, 67, 19-26. doi:10.1016/S0031-9384(99)00064-5

[20] Steimer, T., Python, A., Schulz, P.E. and Aubry, J.M. (2007) Plasma corticosterone, dexamethasone (DEX) suppression and DEX/CRH tests in a rat model of genetic vulnerability to depression. Psychoneuroendocrinology, 32, 575-579. doi:10.1016/j.psyneuen.2007.03.012

[21] Zink, M., Vollmayr, B., Gebicke-Haerter, P.J. and Henn, F.A. (2009) Reduced expression of glutamate transporters vGluT1, EAAT2 and EAAT4 in learned helpless rats, an animal model of depression. Neuropharmacology, 58, 465-447. doi:10.1016/j.neuropharm.2009.09.005

[22] Hansen, C. and Spuhler, K. (1984) Development of the National Institutes of Health genetically heterogeneous rat stock. Alcoholism: Clinical and Experimental Research, 8, 477-479. doi:10.1111/j.1530-0277.1984.tb05706.x

[23] Diaz-Moran, S., Martínez-Membrives, E., López-Aumatell, R., Cañete, T., Blázquez, G., Palencia, M., Mont-Cardona, C., Estanislau, C., Tobeña, A. and Fernández-Teruel, A. (2013) What can we learn on rodent fearfulness/anxiety from the genetically heterogeneous NIH-HS rat stock? Open Journal of Psychiactry, 3, 238-250.
[24] Johannesson, M., López-Aumatell, R., Stridh, P., Diez, M., Tuncel, J., Blázquez, G., Martínez-Membrives, E., Cañete, T., Vicens-Costa, E., Graham, D., Copley, R.R., Hernández-Pliego, P., Beyeen, A.D., Ockinger, J., FernándezSantamaría, C., Gulko, P.S., Brenner, M., Tobeña, A., Guitart-Masip, M., Giménez-Llort, L., Dominiczak, A., Holmdahl, R., Gauguier, D., Olsson, T., Mott, R., Valdar, W., Redei, E.F., Fernández-Teruel A. and Flint, J. (2008) A resource for the simultaneous high-resolution mapping of multiple quantitative trait loci in rats: The NIH heterogeneous stock. Genome Research, 19, 150-158. doi:10.1101/gr.081497.108

[25] Díaz-Morán, S., Palència, M., Mont-Cardona, C., Cañete, T., Blázquez, G., Martínez-Membrives, E., López-Aumatell, R., Tobeña, A. and Fernández-Teruel, A. (2012) Coping style and stress hormone responses in genetically heterogeneous rats: Comparison with the Roman rat strains. Behavioural Brain Research, 228, 203-210. doi:10.1016/j.bbr.2011.12.002

[26] López-Aumatell, R., Guitart-Masip, M., Vicens-Costa, E., Giménez-Llort, L., Valdar, W., Johannesson, M., Flint, J., Tobeña, A. and Fernández-Teruel, A. (2008) Fearfulness in a large N/Nih genetically heterogeneous rat stock: Differential profiles of timidity and defensive flight in males and females. Behavioural Brain Research, 188, 41-55. doi:10.1016/j.bbr.2007.10.015

[27] López-Aumatell, R., Vicens-Costa, E., Guitart-Masip, M., Martínez-Membrives, E., Valdar, W., Johannesson, J., Cañete, T., Blázquez, G., Driscoll, P., Flint, J., Tobeña, A. and Fernández-Teruel, A. (2009) Unlearned anxiety predicts learned fear: A comparison among heterogeneous rats and the Roman rat strains. Behavioural Brain Research, 202, 92-101. doi:10.1016/j.bbr.2009.03.024

[28] López-Aumatell, R., Vicens-Costa, E., Guitart-Masip, M., Martínez-Membrives, E., Valdar, W., Johannesson, M., Cañete, T., Blázquez, G., Giménez-Llort, L., Flint, J., Tobeña, A. and Fernández-Teruel, A. (2009) Ansiedad en ratas genéticamente heterogéneas: Hacia la identificación de genes para caracteres conductuales cuantitativos. Ansiedad y Estrés, 15, 67-84.

[29] López-Aumatell, R., Martínez-Membrives, E., VicensCosta, E., Cañete, T., Blázquez, G., Mont-Cardona, C., Johannesson, M., Flint, J., Tobeña, A. and FernándezTeruel, A. (2011) Effects of environmental and physiological covariates on sex differences in unconditioned and conditioned anxiety and fear in a large sample of genetically heterogeneous (N/Nih-HS) rats. Behavioral and Brain Functions, 7, 48. doi:10.1186/1744-9081-7-48

[30] Vicens-Costa, E., Martínez-Membrives, E., López-Aumatell, R., Guitart-Masip, M., Cañete, T., Blázquez, G., Tobeña, A. and Fernández-Teruel, A. (2011) Two-way avoidance acquisition is negatively related to conditioned freezing and positively associated with startle reactions: A dissection of anxiety and fear in genetically heterogeneous rats. Physiology \& Behavior, 103, 148-156. doi:10.1016/j.physbeh.2010.12.009

[31] Detke, M., Rickels M. and Lucki, I. (1995) Active behaviors in the rat forced swimming test differentially activated by serotonergic and noradrenergic antidepressants. Psychopharmacology, 121, 66-72. 


$$
\text { doi:10.1007/BF02245592 }
$$

[32] Piras, G., Barbato, A., Giorgi, O. and Corda, M. (2010) Effects of antidepressants on the performance in the forced swim test of two psychogenetically selected lines of rats that differ in coping strategies to aversive conditions. Psychopharmacology, 211, 403-414. doi:10.1007/s00213-010-1904-x

[33] Shepherd, J.K., Grewal, S.S., Fletcher, A., Bill, D.J. and Dourish, C.T. (1994) Behavioural and pharmacological characterisation of the elevated "zero-maze" as an animal model of anxiety. Psychopharmacology, 116, 56-64. doi:10.1007/BF02244871

[34] Fernández-Teruel, A., Escorihuela, R.M., Nuñez, J.F., Zapata, A., Boix, F., Salazar, W. and Tobeña, A. (1991) The early acquisition of two-way (shuttle-box) avoidance as an anxiety-mediated behaviour: Psychopharmacological validation. Brain Research Bulletin, 26, 173-176. doi:10.1016/0361-9230(91)90205-X

[35] Gomez, F., Lahmame, A., de Kloet, E.R. and Armario, A. (1996) Hypothalamic-pituitary-adrenal response to chronic stress in five inbred rat strains: Differential responses are mainly located at the adrenocortical level. Neuroendocrinology, 63, 327-337. doi:10.1159/000126973
[36] Paré, W.P. (1992) The performance of WKY rats on three tests of emotional behaviour. Physiology \& Behavior, 51, 1051-1056. doi:10.1016/0031-9384(92)90091-F

[37] Paré, W.P. (1994) Open field, learned helplessness, conditioned defensive burying, and forced swim test in WKY rats. Physiology \& Behavior, 55, 433-439. doi:10.1016/0031-9384(94)90097-3

[38] Solberg, L.C., Olson, S.L., Turek, F.W. and Redei, E. (2001) Altered hormone levels and circadian rhythm of activity in the WKY rat, a putative animal model of depression. American Journal of Physiology, 281, R786R794.

[39] Lahmame, A., Grigoriadis, D.E., De Souza, E.B. and Armario, A. (1997) Brain corticotropinreleasing factor immunoreactivity and receptors in five inbred rat strains: Relationship to forced swimming behaviour. Brain Research, 750, 285-292. doi:10.1016/S0006-8993(96)01368-6

[40] Redei, E., Paré, W.P., Aird, F. and Klucynski, J. (1994) Strain differences in hypothalamic-pituitary-adrenal activity and stress ulcer. American Journal of Physiology, 266, R353-R360. 